Schweiz. Z. Tuberk. 1959;16:121-125

\title{
E. Uehlinger Zum 60. Geburtstag
}

\section{Lieber Freund,}

Durch das gleíche Schícksal verbunden, begegneten wír uns ím Jahre 1929 bei Stöcklín in der Thurgauisch-Schaffhausíschen Heíl-stätte in Davos. Du warst, nach Einführung in die Pathologíe durch Hedínger, Prosektor am Pathologíschen Instítut an der Uníversität Zurich bei von Meyenburg. Während der Kurzeit bereitetest Du die Habílítatíonsschríft vor, welche Dir folgende Laufbahn eröffnete: 1933 Privatdozent und 1939 Títularprofessor an der Med. Fakultät der Uníversität Zurich 1940-53 Chefarzt des Pathologíschen Instítuts des Kantonsspítals St. Gallen 1944-52 Senatsmítglíed der Schweíz. Akademíe für Wíssenschaften. 1950 Studienaufenthalt am Armed Forces Institute of Pathology in Washington.

Prof. E. Uehlinger zum 60. Geburtstag

123

Seít Herbst 1953 ordentlícher Professor für Pathologísche Anatomíe und Allgemeine Pathologíe der Universítät Zurich und Dírektor des Pathologíschen Inslítuts der Uníversítät Zurich. Vor 30 Jahren war beí eínem Kranken mit ojfener Lungentuberku-lose der Endausgang des Leídens ungewíß. War es die eigene Krankheit mit der damít verbundenen, jahrelangen Bedrohung, welches Dein In-teresse der Tuberkulose zuwandte? In unseren ersten Diskussíonen in Davos spíelte der Allergíebegríff eine große Rolle. Von Dír stammte da-mals der Ausdruck «tertíäre psychische Allergies: d.h. seelísche Über-windung der Krankheit. Síe íst Dir gelungen und brachte Dír Gewínn, eínen Gewínn, den Du freígebig weíterverteíltest.

Der Tuberkulose und den Lungenkrankheíten ist rund eín Dríttel Deíner 145 Publíkatíonen gewídmet. Darin wird weniger den morpholo-gíschen Veränderungen als der Gesetzmäßígkeít des Krankheítsverlaufes beím Eínzelnen und in der Kollektívítät nachgegangen. In Gemeínschaftsarbeít mit Deínen Freunden wurde das zeítlíche Intervall festge-stellt, in welchem nach eíner hämatogenen Streuung die Organtuberku-losen auftreten. Díeser Fahrplan der Tuberkulosemanífestatíonen gab für die Begutachtung der Tuberkulose ganz neue Ríchtlíníen. Durch mühsames Sammeln der Krankheítsverläufe von tuberkulösen Zwillings-paaren wurde die Bedeutung der erblíchen Tuberkulosedísposítíon beím Krankheítsverlauf des Eínzelnen dargelegt.Díe Häufigkeít der Tuberkulose in der Zürcher Bevölkerung war von Nägelí am Sektíonsgut des Pathologíschen Instituts Zurich vor 30 Jahren festgestellt worden. Durch Kontrolluntersuchungen am gleíchen Instítut und Vergleíchung mit den epochalen Zahlen Nägelís konntest Du den Rückgang der Tu-berkulosedurchseuchung dokumentíeren. Welche Konsequenzen für die Tuberkuloseepídemíologíe resultíeren, ging aus dem glänzenden Vor-trag an der Jahresversammlung der SVGT in Bern ím Jahre 1942 her-vor: «Díe tuberkulose Späterstínfektíon und íhre Frühevolutíont > . Híer kamen auch die während der Mobílisatíonszeít gemachten Erfahrungen zur Verwertung. Du leístetest während des Weltkrieges der Abteílung für Sanítät als zugeteílter Major große Díenste.

Seít 1948 lehrst Du uns die durch die Eínführung der Tuberkulo-statíka bedíngte Wandlung in der Erscheínungsform der «großen Krankheit)). Experímentelle Erfahrungen mit Rímífon, Arbeíten über Streptomyzín und pathologísche Anatomíe, über die Epídemíologíe des 
Bronchíaldurchbruches tuberkulöser Lymphknoten, über Lungenseg-ment und Lungentuberkulose beeínßußten maßgebend die Klíník und Bekämpfung der Tuberkulose in unserem Lande.

\section{4}

Prof. E. Uehlinger zum 60. Geburtstag

Die Ganzheít Deíner Betrachtungsweíse kommt ím Lehrbuch der Röntgenologíe von SchínzBaensch-Fríedl-Uehlínger und ím Lungen-band des Handbuches für innere Medízín zum Ausdruck. Síe wurde auch Veranlassung, Dír die Chefredaktíon unserer «Schweízeríschen Zeítschríft für Tuberkulose und Pneumonologíe» anzuvertrauen. Unter Deíner Aegíde erhíelt síe Internationale Verbreítung. Auch jenseíts der Grenzen wurden Deíne außergewöhnlíchen Fähígkeíten zur Koordína-tion erkannt. Wirfinden den Namen Uehlinger unter den Herausgebern der «Ergebnísse der gesamten Tuberkulose- und Lungenforschung» und des «Handbuches für Tuberkulose» - um nur auf unserem Spezíal-gebíet zu bleiben.

In Anerkennung Deíner Verdíenste wurdest Du zum Ehrenmit-glíed der Societas Medícorum Fínlandíae und der Österreíchíschen Tuberkulose-Gesellschaft ernannt, bíst Du korrespondíerendes Mítglíed verschíedener ausländischerGesellschaften und zurZeít Vorsítzender der Deutschen Tuberkulose-Gesellschaft. Diese Ehre wurde bis dahín noch nie eínem Ausländer zuteíl.

Es íst erstaunlích, wíe víele praktízíerende Arzte beí Dír, dem soge-nannten theoretíschen Medízíner, Rat für íhre Patienten holen. Jeder Krankheítsfall, jede Begutachtung, kann Gegenstand für eíne tief-schürfende wíssenschaftlíche Publíkatíon werden. Du bíst Dír aber bewußt, daß ínjedem Fall eíne praktísche Lösung gefunden werden muß. Dementsprechend sínd die von Dír erhaltenen Antworten und Schluß-folgerungen ímmer ím täglíchen Leben verwertbar.

Wíe manchmal stelltest Dufest, daß das Zusammentreffen der ver-schiedenen Faktoren in eínem Gutachten víel abenteuerlicher íst, als daß es je von eínem Krímínalschríftsteller ersten Ranges erfunden oder kombíníert werden kònnte. Daraus schòpfst Du den Stoff für Deíne fesselnden Vorträge. Darin wírd - ich denke vor allem an die Vorträge an den Aroser Fortbíldungskursen der Zürcher Kantonalen Tuberku-lose-Líga - das Komplízíerte klar dargestellt, und durch geístreiche Formulíerung werden dem Zuhörer bleíbende Assozíatíonen verschafft.

Das persönlíche Zwíegespräch wírd wegen Deíner Bereítschaft, aus den Erfahrungen des Gesprächspartners zu lernen, eín unauffällíg ge-lenktes Frag- und Antwortspíel, wodurch der Dískussíonsgegenstand die gewünschte Abklärung erhält.

Wer in Deíner Bíblíothek die Büchertítel studiert, staunt über die Víelseítigkeit Deíner Interessen, zu welchen Du in Deínem Elternhause angeregt wurdest. Man begegnet Dír regelmäßíg ím Schauspíelhaus und in Konzerten, und auf Deínen víelen Reisen ist Dír keíne Mühe zu víel, Prof. E. Uehlinger zum 60. Geburtstag

125

Deín Weltbíld durch neue Eíndrücke zu bereíchern. Díese humanístí-sche Gesínnung wírd auch in Fachfragen immer wíeder durch Deine An-teílnahme am menschlíchen Geschick spürbar, und aus der gleíchen Menschlíchkeít heraus pßegst Du sorgfältíg Deine víelen jahrelangen Freundschaften.

Nicht zuletzt Deine körperlíche Leístungsfähígkeít läßt über die 60 Jahre hínwegsehen. Wíe víele gemeínsame Skíabfahrten erlebten wír! Auf tagelangen Wanderungen in den Alpen, ím Jura und ím Schwarz-wald íst níe eine Klage der Müdígkeit zu hören, und als alter Schaff-hauser 
Rheinbub badest Du auch heute noch ínjedem Fluß oder See oder Meer, an dessen Ufer Dích der Weg führt.

Daß Du in eíner so außerordentlích guten seelíschen und kòrperlí-chen Verfassung in das síebente Jahrzehnt eintreten kannst, hast Du nicht zuletzt der Obhut Deíner Dích umsorgenden Gattín zu verdanken. Bei der Erfüllung all Deíner Aufgaben íst sie Dír eine treue Mítarbeíterin. Sie nímmt Dír die Alltagssorgen ab und híndert Dích trotzdem an einem allzu gefährlíchen Wegschweífen von der Wirklíchkeit. Das Erleben und Streben Deíner beíden Töchter verbíndet Dích auf das Innígste mít der Jugend und bewahrt Dír das Verständnís für die zu Dír aufschauenden Studenten.

Líeber Erwín, für Dích íst der 8. August eín Tag wíejeder andere, ein Bíndeglíed von der Vergangenheít zur Zukunft. Uns wírd er aber Anlaß, Dír für das Gegebene zu danken und zu wünschen, daß es Dír vergönnt sein werde, alle in Dír líegenden Möglíchkeíten zu verwírklichen.

Jakob Steiger Albert Wernli-Hässig

Redaktíon und Verlag der «Schweizeríschen Zeítschríft für Tu-berkulose» schlíeßen sích den Glückwünschen Ihrer Freunde an. Sie haben alien Grand, Ihnen für die ausgezeichnete redaktíonelle Füh-rung und stete Förderung der Zeítschríft herzlích zu danken. Sie hojfen, daß Sie in den nächsten Jahren alle Ihre wíssenschaftlíchen Plane verwírklíchen können, und wünschen Ihnen dazu alles Gute für Ihr persönlíches Wohlergehen. 